\title{
PENERAPAN MODEL PEMBELAJARAN KOOPERATIF TIPE JIGSAW TERHADAP PENINGKATAN KEMAMPUAN KONEKSI MATEMATIS SISWA SMA
}

\author{
Mahmud Gustiana $^{1}$, Ari Septian ${ }^{2 *}$, Dwi Arlita Wulandari ${ }^{3}$ \\ 1,2,3 Universitas Suryakancana \\ *ariseptian@unsur.ac.id
}

Diterima: 08 Juni 2020 Disetujui: 30 Juli 2020 Dipublikasikan: 31 Januari 2021

\begin{abstract}
ABSTRAK
Tujuan dari penelitian ini untuk mengetahui peningkatan kemampuan koneksi matematis siswa, sikap siswa, dan hubungan antara sikap siswa dengan peningkatan kemampuan koneksi matematis siswa. Metode yang digunakan quasi experiment dan desain penelitian nonequivalent control group design. Penelitian ini dilaksanakan di SMAN 1 Sukaresmi dengan populasi seluruh siswa kelas X. Pengambilan sempelnya menggunakan teknik purposive sampling sehingga diperoleh kelas X-2 sebagai kelas kontrol dan kelas X-5 sebagai kelas eksperimen. Instrumen yang digunakan yaitu instrumen tes (uraian) dan instrumen non tes (angket sikap). Data diolah dengan menggunakan software IBM SPSS Statistics versi 20 untuk uji normalitas, uji homogenitas, uji kesamaan/perbedaan dua rata-rata dan korelasi Spearman Rho. Hasil penelitian menunjukkan bahwa peningkatan kemampuan koneksi matematis siswa yang belajar dengan menggunakan model pembelajaran kooperatif tipe Jigsaw lebih baik daripada siswa yang belajar dengan pembelajaran konvensional, hampir seluruhnya siswa bersikap positif terhadap model pembelajaran kooperatif tipe Jigsaw, dan terdapat korelasi positif antara sikap siswa terhadap penerapan model pembelajaran kooperatif tipe Jigsaw dengan peningkatan kemampuan koneksi matematis siswa.
\end{abstract}

Kata Kunci :Jigsaw, koneksi matematis

\begin{abstract}
The purpose of this study was to determine the increase in students 'mathematical connection abilities, student attitudes, and the relationship between student attitudes and students' increased mathematical connection abilities. The method used is quasi experiment and research design nonequivalent control group design. This research was conducted at SMAN 1 Sukaresmi with a population of all students of class X. Samples were taken using purposive sampling technique so that class $X-2$ was obtained as the control class and class X-5 as the experimental class. The instruments used were test instruments (description) and non-test instruments (attitude questionnaire). Data were processed using IBM SPSS Statistics version 20 for normality test, homogeneity test, two average similarity / difference test and Spearman Rho correlation. The results showed that increasing the mathematical connection ability of students who learn by using Jigsaw cooperative learning models is better than students who learn with conventional learning, almost all students are positive towards Jigsaw type cooperative learning models, and there is a positive correlation between students' attitudes towards the application of the model Jigsaw type cooperative learning with increasing students' mathematical connection abilities.
\end{abstract}

Keywords: Jigsaw, mathematical connection 


\section{Range: Jurnal Pendidikan Matematika Vol. 2 No. 2 Tahun 2021 Mahmud Gustiana, dkk}

\section{Pendahuluan}

Pendidikan merupakan unsur yang tidak dapat dipisahkan dari kehidupan manusia, ini berarti bahwa setiap manusia berhak mendapat dan berharap untuk selalu berkembang dalam pendidikan. Banyak negara yang maju karena kualitas pendidikannya yang baik, dengan sarana dan prasarana yang memadai, tenaga pengajar yang profesional, kedisiplinan dari berbagai pihak, dan segala sesuatu yang mendukung proses pendidikan sehingga semakin baik(Maskur et al., 2020). Berdasarkan UndangUndang No. 20 Tahun 2003 tentang Sistem Pendidikan Nasional menyatakan bahwa Pendidikan adalah usaha sadar dan terencana untuk mewujudkan suasana belajar dan proses pembelajaran agar peserta didik secara aktif mengembangkan potensi dirinya untuk memiliki kekuatan spiritual keagamaan, pengendalian diri, kepribadian, kecerdasan, akhlak mulia, serta keterampilan yang diperlukan dirinya, masyarakat, bangsa dan Negara(Depdiknas, 2003).

Berdasarkan uraian tersebut memberi gambaran bahwa pendidikan adalah usaha yang sengaja dilakukan demi tercapainya tujuan tertentu. Karena itulah pendidikan harus terencana dengan baik dan agar tujuan dari pendidikan tersebut tercapai. Pemerintah pun terlihat telah berupaya serius melaksanakan pembangunan dalam sektor pendidikan. Hal ini terlihat dengan telah dirumuskannya tujuan pendidikan nasional. Salah satu tujuan pendidikan nasional adalah untuk meningkatkan serta mengembangkan kualitas manusia seutuhnya.

Dalam proses pendidikan, kegiatan pembelajaran merupakan salah satu aspek pokok karena proses belajar yang dialami siswa sebagai peserta didik dan hasil yang dicapai akan turut menentukan pencapaian tujuan pendidikan. Untuk mencapai tujuan tersebut, pembaharuan demi pembaharuan terus dilakukan baik mengenai kurikulum, mata pelajaran, buku pelajaran, pendekatan dan metode mengajar, model pembelajaran, strategi pembelajaran bahkan sampai tenaga kependidikannya. Guru sebagai salah satu komponen dalam proses belajar mengajar merupakan pemegang peran yang sangat penting. Guru tidak hanya sekedar penyampai materi saja, tetapi lebih dari itu guru dapat dikatakan sebagai sentral pembelajaran. Sebagai pengatur sekaligus pelaku dalam proses belajar mengajar, gurulah yang mengarahkan bagaimana proses belajar mengajar itu dilaksanakan. Karena itu guru harus dapat membuat suatu pengajaran menjadi lebih efektif juga menarik sehingga bahan pelajaran yang disampaikan akan membuat siswa merasa senang dan merasa perlu untuk mempelajari bahan pelajaran tersebut.

Salah satu cara agar tercapainya tujuan belajar adalah dengan membagi ilmu pengetahuan yang ingin disampaikan ke dalam beberapa mata pelajaran. Jumlah mata pelajaran yang diberikan setiap jenjang pendidikan tersebut berbeda, disesuaikan dengan kapasitas dan kebutuhan masing-masing jenjang. Mata pelajaran yang selalu ditemui pada setiap jenjang pendidikan adalah matematika. Matematika ialah ilmu tentang bilangan, hubungan antara bilangan. Matematika menduduki peranan yang sangat penting dalam berbagai ilmu pengetahuan di dunia pendidikan(Inayah, Septian, \& Suwarman, 2020). Matematika adalah "King of Science”, rajanya dari ilmu pengetahuan, alasan mengapa matematika dikatakan seperti itu yaitu karena matematika merupakan salah satu bidang studi yang mendukung berbagai perkembangan ilmu pengetahuan dan teknologi. Hal ini dapat dilihat bahwa matematika sebagai salah satu ilmu dasar merupakan mata pelajaran yang wajib diajarkan pada semua jenjang pendidikan, baik sekolah dasar, sekolah menengah maupun perguruan tinggi(Fatwa, Septian, \& Inayah, 2019; Ruseffendi, 2006).

Materi dalam matematika memiliki keterkaitan antara satu unit dengan unit yang lain, oleh karena itu siswa dituntut untuk menguasai meteri secara menyuluruh yakni memahami materi sebelumnya yang menjadi dasar untuk materi selanjutnya. Kemampuan seseorang dalam mengkoneksikan antar unit sangat diperlukan dalam memecahkan masalah matematik. Hal ini tentu memiliki tujuan agar peserta didik mampu berpikir kritis, logis, kreatif, serta mampu mengaitkan masalah-masalah metematika yang sedang dihadapinya (Budiman \& Esvigi, 2017; Sadiyyah, Gustiana, Panuluh, \& Sugiarni, 2019).

Uraian di atas menunjukkan bahwa betapa pentingnya kemampuan koneksi matematis di sekolah. Namun, fakta yang ditemukan di lapangan kemampuan koneksi matematis tersebut masih rendah. Berdasarkan hasil observasi yang dilakukan peneliti dan selama melaksanakan PLP di sekolah, ditemukan 


\section{Range: Jurnal Pendidikan Matematika Vol. 2 No. 2 Tahun 2021 Mahmud Gustiana, dkk}

bahwa nilai rata-rata siswa yang berhubungan dengan koneksi berada di bawah nilai KKM sekolah. Hal ini dapat disebabkan karena beberapa hal, diantaranya adalah karena lemahnya kemampuan koneksi matematis siswa.

Tinggi rendahnya kemampuan siswa mengkoneksikan masalah-masalah metematika menjadi salah satu indikator penting pada pengajaran matematika di sekolah. Siswa terkadang kesulitan menghubungankan materi baru dengan materi lama yang siswa sudah dapatkan sebelumnya. Maka dari itu, untuk meningkatkan kemampuan koneksi matematika pada siswa harus memperhatikan faktor internal dan eksternal. Faktor internal adalah faktor yang berasal dari dalam diri siswa, misalnya kemampuan intelektual. Faktor eksternal adalah faktor yang berasal dari luar siswa, misalnya metode pembelajaran yang dipergunakan guru dalam menyampaikan materi pada pelajaran matematika.

Dalam proses belajar mengajar dikelas khususnya pada saat pelajaran matematika melibatkan berbagai macam aktivitas yang harus dilakukan, terutama jika menginginkan hasil yang optimalagar tercipta suatu kondisi belajar yang aktif, kreatif, efektif dan menyenangkan bagi siswa. Salah satu cara yang dapat dipakai adalah memberi tekanan dalam proses pembelajaran. Hal ini dapat dilaksanakan dengan memilih salah satu model pembelajaran yang tepat karena pemilihan model pembelajaran yang tepat sesuai dengan konsep-konsep mata pelajaran yang akan disampaikan dan pada hakikatnya merupakan salah satu upaya dalam mengoptimalkan koneksi matematis siswa.

Salah satu model pembelajaran yang memungkinkan siswa untuk berinteraksi satu sama lain adalah model pembelajaran kooperatif. Model pembelajaran kooperatif dapat memotivasi siswa, memanfaatkan seluruh energi sosial siswa, saling mengambil tanggung jawab(Septian \& Komala, 2019). Model pembelajaran kooperatif membantu siswa belajar mulai dari keterampilan dasar sampai pemecahan masalah yang kompleks. Model Pembelajaran kooperatif memiliki beberapa tipe. Salah satu tipe model pembelajaran kooperatif yang dapat membangun kepercayaan diri siswa dan mendorong partisipasi mereka dalam kelas adalahModel Pembelajaran Kooperatif Tipe Jigsaw(Hertiavi, Langlang, \& Khanafiyah, 2010; Sugianto, Armanto, \& Harahap, 2014).

Pembelajaran kooperatif tipe Jigsaw merupakan salah satu tipe pembelajaran yang mendorong siswa aktif dan saling membantu dalam menguasai materi pembelajaran untuk mencapai prestasi yang maksimal. Dengan adanya interaksi antar siswa yang menjelaskan materi baru memungkinkan siswa untuk mengkoneksikan sub pokok bahasan materi pelajaran yang sedang dibahas dengan materi yang lain.

Tipe Jigsaw melibatkan seluruh siswa dalam belajar dan sekaligus mengajarkan apa yang dipelajari kepada orang lain. Maka dengan penggunaan model pembelajaran kooperatif tipe Jigsaw dalam pembelajaran matematika diharapkan dapat menghilangkan rasa bosan siswa dalam belajar. Siswa dapat saling bertukar pikiran dengan teman. Hal ini akan membuat kelas lebih hidup dan menyenangkan, sehingga siswa akan lebih serius belajar.

Melalui model pembelajaran Jigsaw diharapkan dapat memberikan solusi dan suasana baru yang menarik dalam pembelajaran sehingga memberikan konsep pemahaman baru(Tarigan \& Surya, 2017). Siswa bekerja dengan sesama siswa sehingga memiliki banyak kesempatan untuk mengolah informasi dan meningkatkan keterampilan koneksi dan berkomunikasi. Alasan lain yang menyebabkan model pembelajaran kooperatif tipe Jigsaw perlu diterapkan sebagai model pembelajaran yaitu tidak adanya persaingan antar siswa atau kelompok. Mereka bekerjasama untuk menyelesaikan masalah dalam mengatasi cara berpikir yang berbeda(Rizkiani, Astri. Ari, 2019). Siswa dalam kelompok bertanggung jawab atas penguasaan materi belajar yang ditugaskan padanya lalu mengajarkan bagian tersebut pada anggota yang lain. Siswa juga senantiasa tidak hanya mengharapkan bantuan dari guru serta siswa termotivasi untuk belajar cepat dan akurat seluruh materi. Berdasarkan beberapa pandangan dan permasalahan di atas, maka penelitian ini bertujuan untuk memperbaiki dan meningkatkan kemampuan koneksi matematis siswa. 


\section{Range: Jurnal Pendidikan Matematika Vol. 2 No. 2 Tahun 2021 Mahmud Gustiana, dkk}

\section{Metode Penelitian}

Perlakuan yang diberikan pada penelitian ini adalah pembelajaran dengan menggunakan Model Kooperatif Tipe Jigsaw, sedangkan aspek yang diukur adalah kemampuan koneksi matemati siswa. Desain penelitian eksperimen kuasi yang digunakan dalam penelitian ini adalah Nonequivalent Control Group Design. Pada desain ini terdapat dua grup yang tidak dipilih secara random atau sudah ditentukan, kemudian diberi pretest (tes awal) untuk mengetahui keadaan awal (kemampuan awal) antara grup eksperimen dan grup kontrol. Grup eksperimen diberi perlakuan khusus, sedangkan grup kontrol tanpa perlakuan. Setelah itu dilakukan posttest (tes akhir) dan dibandingkan peningkatannya.

Penelitian ini dilaksanakan di SMA Negeri 1 Sukaresmi dengan populasi penelitian seluruh siswa kelas X yang secara keseluruhan populasi terdiri dari 9 kelas. Dari 9 kelas yang ada di lokasi penelitian, dengan teknik purposive sampling diperoleh sampel yaitu kelas X-5 sebagai kelas eksperimen dan kelas $\mathrm{X}-2$ sebagai kelas kontrol.

Adapun instrumen yang digunakan dalam penelitian ini adalah instrumen tes berupa 5 butir soal uraian dan instrumen non tes berupa angket skala sikap yang terdiri dari 11 pernyataan positif dan 9 pernyataan negatif. Instrumen tes terlebih dahulu diuji cobakan pada siswa yang telah menerima materi pelajaran yang digunakan dalam penelitian. Kemudian di olah menggunakan software Anates Uraian Versi 4.0.5, hal ini bertujuanuntuk mengetahui validitas, reliabilitas, tingat kesukaran dan daya pembeda. Adapun angket yang digunakan dalam penelitian ini berupa pernyataan-pernyataan tertutup sehingga responden tinggal memilih jawaban yang sesuai. Angket terdiri dari empat kategori sikap yaitu Sangat Setuju (SS), Setuju (S), Tidak Setuju (TS), dan Sangat Tidak Setuju (STS). Pengisian angket dilakukan setelah pembelajaran matematika dengan menggunakan model pembelajaran tipe Jigsaw selesai.

Data yang akan diolah dan dianalisis dalam penelitian ini yaitu berupa pretest, postest, indeks gain, dan korelasi dengan menggunakan software IBM SPSS Statistics versi 20. Adapun pengolahan angket yaitu dengan mempresentasikan jumlah responden dari masing-masing pilihan jawaban dengan menggunakan Software Microsoft Excel 2010. Untuk menentukan sikap siswa terhadap setiap pernyataan pada angketmengenai model pembelajaran kooperatif tipe Jigsaw digunakan modus yaitu jumlah responden terbanyak pada pilihan sikap dari setiap pernyataan.

\section{Hasil Penelitian dan Pembahasan}

\section{Peningkatan Kemampuan Koneksi Matematis Siswa}

Pelaksanaan Model Pembelajaran Kooperatif Tipe Jigsaw untuk Peningkatan Kemampuan koneksi matematis siswa adalah sebagai berikut :

Untuk meningkatkan kemampuan pemecahan masalah dalam pembelajaran kooperatif tipe Jigsaw dilakukan pemberian soal yang bertujuan meningkatkan kemampuan pemecahan masalah. Soal-soal tersebut diberikan sebelum pelaksanaan pembelajaran di kelas dan saat tes akhir siklus. Soal-soal yang diberikan dalam langkah tersebut berupa soal uraian. Usaha yang dilakukan guru untuk meningkatkan kemampuan pemecahan masalah siswa adalah mengusahakan pemberian soal-soal yang berisi kemampuan pemecahan masalah dengan menggunakan bahasa yang mudah dimengerti siswa dan isinya pun disesuaikan dengan materi yang dipelajari. Berikut adalah deskripsi statistika data pretest :

Tabel 1. Deskripsi Statistik Data Pretest

\begin{tabular}{lccccc}
\hline Kelas & $\begin{array}{c}\text { Skor } \\
\text { Ideal }\end{array}$ & Min & Max & Mean & $\begin{array}{c}\text { Std. } \\
\text { Dev }\end{array}$ \\
\hline Ekperimen & 20 & 4 & 12 & 7,8 & 1,762 \\
\hline Kontrol & 20 & 2 & 9 & 7,03 & 1,647 \\
\hline
\end{tabular}




\section{Range: Jurnal Pendidikan Matematika Vol. 2 No. 2 Tahun 2021 Mahmud Gustiana, dkk}

Berdasarkan Tabel 1, diperoleh rata-rata skor pretest kelas eksperimen adalah 7,80 dengan standar deviasi 1,762. Untuk kelas kontrol diperoleh rata-rata 7,03 dengan standar deviasi 1,647. Dari deskripsi data tersebut terlihat bahwa kemampuan kelas eksperiman lebih baik daripada kemampuan kelas kontrol. Secara keseluruhan kemampuan kedua kelas tidak jauh berbeda. Untuk mengetahui sama atau tidaknya kemampuan pemahaman matematis awal pada kedua kelas tersebut dilakukan analisis uji statistik kesamaan dua rata-rata independen. Sebelum dilakukan uji kesamaan dua rata-rata independen data pretest, terlebih dahulu dilakukan uji normalitas distribusi populasi dan homogenitas varians.

Tabel 2. Hasil Uji Normalitas Distribusi Populasi Data Pretest

\begin{tabular}{lcccc}
\hline \multirow{2}{*}{ Kelas } & \multicolumn{5}{c}{ Shapiro-Wilk } \\
\cline { 2 - 5 } & Statistic & Df & Sig. & Ket. \\
\hline Eksperimen & 0,953 & 35 & 0,141 & Normal \\
\hline Kontrol & 0,889 & 36 & 0,002 & Tidak Normal \\
\hline
\end{tabular}

Dari hasil uji normalitas distribusi populasi dari Shapiro-Wilk yang terdapat pada Tabel 2, diperoleh nilai signifikansi untuk kelas eksperimen sebesar 0,141 sedangkan untuk kelas kontrol diperoleh nilai signifikansi sebesar 0,002. Ini berarti data pretest kelas kontrol berasal dari populasi yang berdistribusi tidak normal, dimana $0,002<0,005$. Sedangkan untuk data pretest kelas eksperimen berasal dari populasi yang berdistribusi normal.

Karena salah satu data pretest penelitian berasal dari populasi yang berdistribusi tidak normal, maka tidak akan dilakukan uji homogrnitas varians. Pengujian yang akan dilakukan selanjutnya adalah Two-Independent Samples Test, Mann-Whitney dalam software IBM SPSS Statistics versi 20.

Tabel 3. Hasil Uji Kesamaan Dua Rata-rata Nilai Pretest
\begin{tabular}{lr}
\multicolumn{2}{c}{ Test Statistics } \\
\hline \multicolumn{2}{c}{ Pretest } \\
\hline Mann-Whitney U & 488,000 \\
\hline Wilcoxon W & 1154,000 \\
\hline Z & $-1,675$ \\
\hline $\begin{array}{l}\text { Asymp. Sig. (2- } \\
\text { tailed) }\end{array}$ & 0,094 \\
\hline
\end{tabular}

Dari hasil uji kesamaan dua rata-rata independen yang terdapat pada Tabel 3, diperoleh nilai signifikansi 0,094. Nilai tersebut lebih besar dari 0,05 maka $\mathrm{H}_{0}$ diterima. Dengan demikian dapat disimpulkan bahwa kemampuan awal koneksi matematis siswa kelas eksperimen sama dengan kemampuan awal koneksi matematis siswa kelas kontrol.

Tabel 4. Deskripsi Statistik Data Indeks Gain

\begin{tabular}{lccccc}
\hline Kelas & $\begin{array}{c}\text { Jumlah } \\
\text { Siswa }\end{array}$ & Min & Max & Mean & $\begin{array}{c}\text { Std. } \\
\text { Dev }\end{array}$ \\
\hline Ekperimen & 35 & 0,36 & 1 & 0,83 & 1,722 \\
\hline Kontrol & 36 & 0,27 & 1 & 0,71 & 0,202 \\
\hline
\end{tabular}




\section{Range: Jurnal Pendidikan Matematika Vol. 2 No. 2 Tahun 2021 Mahmud Gustiana, dkk}

Berdasarkan Tabel 4, diperoleh rata-rata skor indeks gain kelas eksperimen adalah 0,83 dengan standar deviasi 1,722. Sedangkan untuk kelas kontrol diperoleh rata-rata 0,71 dengan standar deviasi 0,202. Dari deskripsi data tersebut terlihat bahwa skor rata-rata kelas eksperimen lebih besar daripada skor rata-rata kelas kontrol. Namun, untuk mengetahui ada atau tidaknya perbedaan rata-rata peningkatan kemampuan koneksi matematis pada kedua kelas tersebut dilakukan analisis uji statistik perbedaan dua rata-rata independen. Sebelum dilakukan uji perbedaan dua rata-rata independen data indeks gain, terlebih dahulu dilakukan uji normalitas distribusi populasi dan homogenitas varians.

Tabel 5. Hasil Uji Normalitas Distribusi Populasi Data Indeks Gain

\begin{tabular}{lcccc}
\hline \multirow{2}{*}{ Kelas } & \multicolumn{5}{c}{ Shapiro-Wilk } \\
\cline { 2 - 5 } & Statistic & df & Sig. & Ket. \\
\hline Eksperimen & 0,872 & 35 & 0,001 & Tidak Normal \\
\hline Kontrol & 0,931 & 36 & 0,026 & Tidak Normal \\
\hline
\end{tabular}

Dari hasil uji normalitas distribusi populasi dari Shapiro-Wilk yang terdapat pada Tabel 5, diperoleh nilai signifikansi untuk kelas eksperimen sebesar 0,001 sedangkan untuk kelas kontrol diperoleh nilai signifikansi sebesar 0,026. Karena kedua kelas mempunyai nilai Sig. yang < 0,05 maka $\mathrm{H}_{0}$ ditolak. Ini berarti data nilai indeks gain kedua kelas berasal dari populasi yang berdistribusi tidak normal.

Karena data indeks gain penelitian berasal dari populasi yang berdistribusi tidak normal, maka tidak akan dilakukan uji homogrnitas varians. Pengujian yang akan dilakukan selanjutnya adalah TwoIndependent Samples Test, Mann-Whitney dalam software IBM SPSS Statistics versi 20.

Tabel 6. Hasil Uji Mann Whitney Nilai Indeks Gain

\begin{tabular}{lr}
\hline \multicolumn{2}{c}{ Test Statistics ${ }^{\mathrm{a}}$ (Gain) } \\
\hline Mann-Whitney U & 402 \\
\hline Wilcoxon W & 1068 \\
\hline Z & $-2,64$ \\
\hline Asymp. Sig. (2-tailed) & 0,008 \\
\hline
\end{tabular}

Berdasarkan Tabel 6 diperoleh nilai signifikansinya adalah 0,008 (uji dua pihak). Namun, uji Mann Whitneyindeks gain ini menggunakan uji satu pihak, maka Sig. (2-tailed) harus dibagi dua. Sehingga nilai Sig. Menjadi 0,004 dimana nilai tersebut < 0,05, maka $\mathrm{H}_{0}$ ditolak. Maka,dapat disimpulkan bahwa peningkatan kemampuan koneksi matematis kelas eksperimen lebih baik daripada kelas kontrol. Hal ini disebabkan oleh pembelajaran dengan model kooperatif tipe Jigsaw memberikan tingkat aktivitas yang berbeda dari pembelajaran konvensional. Siswa lebih aktif dalam belajar, banyak bertanya, berkerjasama denga teman kelompoknya, berani menyampaikan hasil pekerjaan di depan kelas, dan lebih menarik(Fatwa et al., 2019).

\section{Respon Siswa dalam Menggunaan Model Pembelajaran Kooperatif Tipe Jigsaw}

Analisis data hasil angket skala sikap siswa dilakukan dengan tujuan untuk melihat sikap siswa terhadap proses pembelajaran dengan menggunakan model kooperatif tipe Jigsaw yang diberikan kepada kelas eksperimen.

Angket diberikan pada siswa kelas eksperimen yang terdiri dari 20 butir pernyataan, dengan 11 butir pernyataan positif dan 9 pernyataan negatif. Pernyataan angket skala sikap ini juga dibagi dalam beberapa 


\section{Range: Jurnal Pendidikan Matematika Vol. 2 No. 2 Tahun 2021 Mahmud Gustiana, dkk}

variabel dan indikator, yaitu dengan tiga variabel yang terdiri dari skala sikap terhadap mata pelajaran matematika, skala sikap terhadap pembelajaran matematika dengan menggunakan model kooperatif tipe Jigsaw, dan skala sikap terhadap soal-soal kemampuan koneksi matematis. Variabel-variabel tersebut juga dibagi kembali dalam beberapa indikator.

Adapun secara keseluruhan sikap siswa terhadap pembelajaran dengan menggunakan model kooperatif tipe Jigsawdapat dilihat pada tabel 7.

Tabel 7. Rekapitulasi Sikap Siswa Secara Keseluruhan

\begin{tabular}{cccc}
\hline \multirow{2}{*}{ Indikator } & \multicolumn{2}{c}{ Rekapitulasi Jawaban Angket } & \\
\cline { 2 - 3 } & $\begin{array}{c}\text { Persentase } \\
\text { Sikap Positif }\end{array}$ & $\begin{array}{c}\text { Persentase Sikap } \\
\text { Negatif }\end{array}$ & Ket. \\
\hline 1 & 86,43 & 13,57 & $\begin{array}{c}\text { Hampir } \\
\text { Seluruhnya Positif }\end{array}$ \\
\hline 2 & 89,84 & 10,48 & $\begin{array}{c}\text { Hampir } \\
\text { Seluruhnya Positif }\end{array}$ \\
\hline 3 & 87,35 & 12,65 & $\begin{array}{c}\text { Hampir } \\
\text { Seluruhnya Positif }\end{array}$ \\
\hline Jumlah & 263,62 & 36,7 & $\begin{array}{c}\text { Hampir } \\
\text { Seluruhnya Positif }\end{array}$ \\
\hline Rata-rata & 87,87 & 12,23 & $\begin{array}{c}\text { Hampir } \\
\text { Seluruhnya Positif }\end{array}$ \\
\hline
\end{tabular}

Dari Tabel 7 diperoleh rekapitulasi angket dari setiap indikator didapatkan modus persentase sikap siswa sebesar 87,87 \% yaitu pada sikap positif, maka dapat diartikan bahwa hampir seluruhnya siswa bersikap positif terhadap pembelajaran matematika, terhadap pembelajaran matematika dengan menggunakan model kooperatif tipe Jigsaw, dan terhadap soal-soal kemampuan koneksi matematis. Sikap positif siswa diakibatkan oleh pembelajaran yang menarik dan terjadi transfer ilmu dari temantemannya (Tarigan \& Surya, 2017). Sehingga siswa menjadi senang dan bersikap positif terhadap pembelajaran (Anggriani \& Septian, 2019).

\section{Hubungan Antara Sikap Siswa dengan Peningkatan Kemampuan Koneksi Matematis Siswa}

Analisis ini dilakukan untuk mengetahui apakah ada hubungan yang positif antara sikap siswa terhadap penerapan model kooperatif tipe Jigsaw dengan peningkatan kemampuan koneksi matematis siswa. Teknik korelasi yang digunakan adalah korelasi bivariateyaitu dengan uji korelasi Spearman Rho. Data yang dikorelasikan yaitu data hasil analisis skala sikap siswa dan data indeks gain.Setelah diolah menggunakan bantuan software IBM SPSS Statistics versi 20 didapat output analisis korelasi sebagai berikut.

Berdasarkan hasil perhitungan, didapatkan Sig. $(2$ tailed $)=0,000$. Oleh karena 0,000 $<0,05$ maka $H_{0}$ ditolak. Dengan demikian dapat dikatakan bahwa terdapat hubungan positif antara sikap siswa terhadap penerapan model pembelajaran kooperatif tipe Jigsaw dengan peningkatan kemampuan koneksi matematis siswa. Nilai koefisien korelasi sebesar 0,729 sehingga korelasinya diinterpretasikan kuat. Dari nilai koefisien korelasi tersebut dapat diperoleh nilai keofisien determinasi yaitu sebesar 53,14\%. Ini menunjukan bahwa sikap siswa berpengaruh terhadap peningakatan kemampuan koneksi matematis siswa sebesar 53,14\%. 


\section{Range: Jurnal Pendidikan Matematika Vol. 2 No. 2 Tahun 2021 Mahmud Gustiana, dkk}

Peningkatan koneksi matematis didorong oleh sikap siswa dalam pembelajaran. Efek yang diberikan sangat mempengaruhi kemampuan koneksi matematis siswa(Anita, 2014; Septian \& Komala, 2019; Ulya, I. F., Irawati, R., 2016).

\section{Kesimpulan}

Peningkatan kemampuan koneksi matematis siswa yang belajar dengan menggunakan model pembelajaran kooperatif tipe Jigsaw lebih baik daripada siswa yang menggunakan pembelajaran konvesional, pada umunya sikap siswa terhadap penerapan model pembelajaran kooperatif tipe Jigsaw adalah positif, dan terdapat hubungan positif antara sikap siswa terhadap penerapan model pembelajaran kooperatif tipe Jigsaw dengan peningkatan kemampuan koneksi matematis siswa.

\section{Ucapan Terima Kasih}

Terima kasih kami ucapkan kepada sekolah yang telah mengijinkan kami dalam melakukan penelitian. Tak lupa pula kami sampaikan terima kasih pada pihak Universitas dan Program Studi Pendidikan Matematika Universitas Suryakancana sudah mendukung selama kami melakukan penelitian.

\section{Daftar Pustaka}

Anggriani, A., \& Septian, A. (2019). Peningkatan Kemampuan Komunikasi Matematis dan Kebiasaan Berpikir Siswa Melalui Model Pembelajaran IMPROVE. IndoMath: Indonesia Mathematics Education, 2(2), 105. https://doi.org/10.30738/indomath.v2i2.4550

Anita, I. W. (2014). PENGARUH KECEMASAN MATEMATIKA (MATHEMATICS ANXIETY) TERHADAP KEMAMPUAN KONEKSI MATEMATIS SISWA SMP. Infinity Journal. https://doi.org/10.22460/infinity.v3i1.43

Arikunto. (2019). Metodelogi Penelitian, Suatu Pengantar Pendidikan. In Rineka Cipta, Jakarta (p. 21).

Budiman, H., \& Esvigi, I. (2017). IMPLEMENTASI STRATEGI MATHEMATICAL HABITS OF MIND (MHM) BERBANTUAN MULTIMEDIA UNTUK MENINGKATKAN KEMAMPUAN BERPIKIR KRITIS SISWA. PRISMA, 6(1). https://doi.org/10.35194/jp.v6i1.26

Depdiknas. (2003). Undang-Undang RI No 20 Tahun 2003. In Undang-Undang Republik Indonesia Nomor 20 Tahun 2003 Tentang Sistem Pendidikan Nasional Dengan Rahmat Tuhan Yang Maha Esa Presiden Republik Indonesia.

Fatwa, V. C., Septian, A., \& Inayah, S. (2019). Kemampuan Literasi Matematis Siswa melalui Model Pembelajaran Problem Based Instruction. Mosharafa: Jurnal Pendidikan Matematika, 8(3), 389398.

Hertiavi, M. A., Langlang, H., \& Khanafiyah, S. (2010). Penerapan Model Pembelajaran Kooperatif Tipe Jigsaw Untuk Peningkatan Kemampuan Pemecahan Masalah Siswa SMP. Jurnal Pendidikan Fisika Indonesia, 6(1). https://doi.org/10.15294/jpfi.v6i1.1104

Inayah, S., Septian, A., \& Suwarman, R. F. (2020). Student Procedural Fluency in Numerical Method Subjects. Desimal: Jurnal Matematika, 3(1), 53-64. https://doi.org/10.24042/djm.v3i1.5316

Maskur, R., Sumarno, Rahmawati, Y., Pradana, K., Syazali, M., Septian, A., \& Palupi, E. K. (2020). The effectiveness of problem based learning and aptitude treatment interaction in improving mathematical creative thinking skills on curriculum 2013. European Journal of Educational Research, 9(1), 375-383. https://doi.org/10.12973/eu-jer.9.1.375

Rizkiani, Astri. Ari, S. (2019). Kemampuan Metakognitif Siswa SMP dalam Pembelajaran Matematika dengan Menggunakan Pendekatan Realistic Mathematics Education ( RME ). UNION: Jurnal Pendidikan Matematika, 7(2), 275-284.

Ruseffendi, E. . T. . (2006). Pengantar kepada Membantu Guru Mengembangkan Kompetensinya dalam 


\section{Range: Jurnal Pendidikan Matematika Vol. 2 No. 2 Tahun 2021 Mahmud Gustiana, dkk}

Pengajaran Matematika untuk Meningkatkan CBSA. (2001), 8410092.

Sadiyyah, R., Gustiana, M., Panuluh, S. D., \& Sugiarni, R. (2019). PENGEMBANGAN LEMBAR KERJA SISWA (LKS) DENGAN PENDEKATAN INKUIRI TERBIMBING BERBASIS MOBILE LEARNING UNTUK MENGOPTIMALKAN KEMAMPUAN BERPIKIR KRITIS MATEMATIS. PRISMA, 8(1), 80. https://doi.org/10.35194/jp.v8i1.616

Septian, A. (2013). Pengaruh Kemampuan Prasyarat terhadap Kemampuan Penalaran Matematis Mahasiswa dalam Matakuliah Analisis Real. In Atikan (Vol. 4). Retrieved from http://www.mindamas-journals.com/index.php/atikan/article/view/16

Septian, A., \& Komala, E. (2019). Kemampuan Koneksi Matematik dan Motivasi Belajar Siswa dengan Menggunakan Model Problem-Based Learning (PBL) Berbantuan Geogebra di SMP. PRISMA, 8(1), 1-13. https://doi.org/10.35194/jp.v8i1.438

Sugianto, Armanto, D., \& Harahap, M. B. (2014). Perbedaan Penerapan Model Pembelajaran Kooperatif Tipe Jigsaw dan STAD Ditinjau dari Kemampuan Penalaran dan Komunikasi Matematis Siswa SMA. Jurnal Didaktik Matematika, 1(1), 113-128.

Sugiyono. (2017). Pendekatan Kuantitatif, Kualitatif, Kombinasi, R\&D dan Penelitian Evaluasi. In Metodelogi Penelitian (pp. 147-148).

Tarigan, F. A. P., \& Surya, E. (2017). The Application of Cooperative Learning Model of Jigsaw Type to Increase Activity And Student Learning Results In Learning Phytagoras Theorem. IJARIIE: International Journal of Advance Research and Innovative Ideas in Education, 3(3), 882-891.

Ulya, I. F., Irawati, R., \& M. (2016). Peningkatan Kemampuan Koneksi Matematis dan Motivasi Belajar Siswa Menggunakan Pendekatan Kontekstual. PENINGKATAN KEMAMPUAN KONEKSI MATEMATIS DAN MOTIVASI BELAJAR SISWA MENGGUNAKAN PENDEKATAN KONTEKSTUAL, 1(1), 121-130. https://doi.org/10.23819/pi.v1i1.2940 